\title{
ANALISIS INSIDE PASS TIM BOLA BASKET PUTERI UNIVERSITAS NEGERI JAKARTA PADA LIMA BASKETBALL NATIONALS 2019
}

\author{
Eliya Novanti ${ }^{1}$ \\ Iman Sulaiman ${ }^{2}$ dan Tirto Apriyanto ${ }^{3}$
}

Fakultas Ilmu Keolahragaan Universitas Negeri Jakarta

$\underline{\text { elianovanti@gmail.com }}^{1}, \underline{\text { isulaiman@unj.ac.id }}{ }^{2},{\underline{\text { tapriyanto@ } \text { unj.ac.id }^{3}}}^{3}$

\begin{abstract}
ABSTRAK
Penelitian ini bertujuan untuk mengetahui bagaimana inside pass tim bola basket putri Universitas Negeri Jakarta pada Liga Mahasiswa Basketball Nationals 2019. Metode dalam penelitian ini termasuk dalam metode deskriptif dengan teknik pengambilan data observasi atau survei, populasi dalam penelitian ini adalah seluruh tim bola basket putri yang bertanding pada Liga Mahasiswa Basketball Nationals 2019 dan sampel yang di gunakan yaitu total sampling yaitu seluruh pemain putri Universitas Negeri Jakarta yang bertanding pada liga Mahasiswa Basketball Nationals yang berjumlah 12 orang. Berdasarkan hasil dari analisis Peneliti Inside Pass yang dilakukan oleh Universitas Negeri Jakarta inside pass yang dilakukan tim bola basket UNJ selama mengikuti Liga Mahasiswa Basketball Nationals 2019 sudah baik bagaimana Inside Pass Ini tujuannya mengarahakan bola ke area circle lawan dan berusaha mencetak point dari jarak yang lebih dekat dengan ring tingkat keberhasilan mencapai $69 \%$ dan kegagalan $31 \%$ dan berdasarkan data yang diperoleh peluang untuk finishing rata-rata mecapai 71 kali atau $42 \%$, Hasil analisis ini bisa dijadikan salah satu strategi oleh UNJ dalam membuat system penyerangan yang mengutamakan Inside Pass.
\end{abstract}

Kata Kunci : Analisis,keberhasilan dan kegagala, Inside Pass.

\section{ABSTRACT}

This study aims to determine how inside pass of the girl basketball team at University of Jakarta in the Basketball Nationals Student League 2019. The method in this study was included in the descriptive method with observation or survey data collection techniques. The population in this study were all girl basketball teams that competed in the Basketball Nation Student League 2019 and the sample used was total sampling, namely all girl players Universiyty of Jakarta who competed in the Basketball Nationals Student League, amounting to 12 people.Based on the results of the analysis of Inside Pass Researchers conducted by University of Jakarta while participating in the Basketball Nationals Student League 2019, it is good how Inside Pass aims to direct the ball at the opponent's circle area and try to score points from a distance that is closer to the ring, the success rate reaches $69 \%$ and $31 \%$ failure and based on the data obtained the opportunity for finishing on average reaches 71 times or $42 \%$. The results of this analysis can be used as a strategy by University of Jakarta in creating an attack system that prioritizes Inside Pass.

Keywords : Analysis, success and failure, Inside Pass.

\section{PENDAHULUAN}

Dengan perkembangan bola bsket yang begitu pesat ditanah air menjadikan begitu banyaknya kompetisi yang diadakan. Kompetisi ditingkat mahasiswa yang dianggap sudah semi profesional menjadikan setiap pemain di Universitas untuk mengirimkan atlet nya yang terbaik dalam mengikuti kompetisi. 
Berdasarkan hasil penelitian kecil yang dilakukan terhadap atlet basket puteri Universitas Negeri Jakarta yang mengikuti kompetisi di Gunadarma hopp summit vol 6 yang digelar pada tanggal 6 sampai dengan tanggal 16 Nopember 2019 hanya mampu lolos sampai dengan perdelapan final. Universitas Negeri Jakarta yang rata-rata memiliki pemain yang fisiknya tidak terlalu besar kesulitan untuk mencetak angka di dalam circle yang akhirnya lebih banyak melakukan finishing di luar circle yang tidak jarang sulit menghasilkan angka.

Dari empat game yang telah mereka jalani hanya mampu melakukan Inside Pass total 121 kali. Dari 121 kali tersebut Universitas Negeri Jakarta berhasil melakukan 40 kali inside pass dan 81 kali gagal dalam melakukan inside pass. Artinya tingkat keberhasilan mencapai $33,05 \%$ dan kegagalan mencapai $66,95 \%$ dalam hal ini kegagalan lebih besar dibandingkan dengan keberhasilan. Inside Pass merupakan salah satu teknik dasar yaitu passing. Passing merupakan salah satu teknik dasar yang Penting dimana permainan basket olahraga yang dominan dengan teknik tersebut. oleh karena adanya kesenjangan tersebut maka penulis bermaksud untuk meneliti mengenai Inside Pass .

Inside Pass atau passing ke dalam ini tidak hanya ditentukan dengan kualitas passing saja tetapi bagaimana setiap pemain mampu melakukan gerakan yang efektif dan dapat menciptakan peluang agar pemain yang memegang bola dapat melakukan passing ke dalam circle. Dalam kasus yang terjadi di tim basket puteri Universitas Negeri Jakarta ini pemain kesulitan untuk melakukan gerakan kearah circle dan sulitnya melakukan passing karena pemain dijaga dengan ketat sehingga pemain yang memegang bola kesulitan untuk melakukan passing ke dalam, dan ketika ada peluang dalam melakukan passing ke dalam banyak pemain yang tidak siap dalam menangkap bola sehingga hal tersebut dapat merugikan tim bahkan tidak jarang lawan dapat melakukan Fast break dan mencetak angka dengan mudah.

Kemungkinan yang terjadi pada tim UNJ yaitu Program latihan dan jumlah pertandingan atau jam terbang yang kurang. Mengingat para pemain yang ikut dalam kompetisi tersebut dominan oleh para pemain baru yaitu mahasiswi angkatan pertaamana dan kedua yang masih kurang dalam hal jam terbang. Dengan adanya beberapa aspek yang telah disebutkan diatas diharapkan menjadi sebuah tolak ukur bagi setiap tim bola basket,dimana aspek tersebut menjadi asapek yang menentukan kesiapan tim dalam mengikuti pertandingan,sehingga saat pertandingan berlangsung dapat menuai kemenangan.

Bola basket adalah salah satu olahraga paling popular di dunia, keterampilanketerampilan perseorangan seperti tembakan umpan, dribble dan rebound serta kerjasama tim untuk menyerang atau bertahan adalah persyaratan agar berhasil dalam memainkan olahraga ini. Selain olahraga ini mudah di mainkan saat ini olahraga basket menjadi salah satu yang wajib hadir di kurikulum setiap satuan pendidikan,para siswa di perkenalkan pola gerak serta teknik dasar dalam permainan basket.

Bola basket dimainkan oleh dua regu yang masing-masing terdiri dari 5 orang pemain,tiap-tiap regu berusaha memasukan bola ke dalam keranjang regu lawan dan mencegah lawan memasukan bola atau membuat angka.(Muhajir dan Much., 2007)

Komponen fisik yang dominan dalam bola basket yaitu, Speed endurance. Speed (Kecepatan) adalah kemampuan seseorang untuk pindah tempat dari satu titik lain dalam waktu sesingkatsingkatnya.(Ambarukmini. et al., 2007) Oleh karena itu pemain basket harus memiliki endurance yang baik.

Namun karena basket adalah olahraga yang kompleks maka hampir semua komponen fisik ada dalam olahraga ini yaitu strength, endurance, speed, agility, power, koordinasi, balance, akurai, reaksi, dan flexibility.

Permainan ini memiliki berbagai posisi seperti,point guard,shooting guard, power forward, small forward dan centre. Dari masing-masing posisi tersebut setiap pemain memiliki tugasnya masing-masing seperti 1) point guard (best ball handler), bertugas mengatur penyerangan,bagaimana 
menjalankan system permainan dengan baik dan menjadi titik awal dimulainya suatu serangan. 2) shooting guard (best outside shooter), bertugas untuk mencetak angka dari jarak jauh ketika posisi memungkinkan untuk melakukan tembakan. 3) small forward (versatile inside and outside player) pemain yang memiliki kecepatan,kuat bertahan di dalam dan di luar. 4) power forward (strong rebounding forward) baik dalam hal rebound 5) Centre sebagai pemain tengah (inside scorer, rebounder and shot blocker) yang bertugas untuk mencetak angka di bawah ring dan memiliki postus yang tinggi,besar dan kuat dalam rebound.Berdasarkan pembagian posisi tersebut setiap tim harus memiliki pemain yang baik untuk memenuhi setiap posisi apalagi dalam pertandingan tingkat mahasiswa yang notabennya sudah semi professional.

Inside pass adalah passing yang sudah memiliki tujuan dalam permainan karena passing tersebut diarahkan langsung kedaerah pertahanan lawan dan bertujuan untuk mencetak point.(Iman sulaiman, 2019) Inside pass berfokus pada pegerakan, passing dan finishing.(Rose, 2013), selain itu kunci dalam melakukan Inside Pass yaitu mengeksekusi diwaktu yang tepat.(Rose, 2013)

Berdasarkan pengertian diatas ada beberapa tingkat Keberhasilan inside pass,(Wissel, 2012) 1) Pergerakan pemain,pergerakan ini dilihat apakah pemain dalam posisi yang bebas dan bisa menerima passing 2)Timing passing ,kesesuaian anatara pergerakan dan waktu yang tepat dalam melakukan passing 3) Penerima bola atau good catching agar bola tidak terlepas, Jika hal tesebut dapat dipenuhi maka tim akan dengan mudah untuk dapat mencetak angka.

Selain itu terdapat beberapa kegunaan Inside pass yang di dapat diantaranya yaitu 1) Mendapatkan peluang untuk menciptakan score dari dalam circle, 2) Merusak pertahanan dari luar dan dalam, 3) Passing yang berbahaya karena diarahkan langsung ke circle area untuk mencetak angka.(Dr Iman Sulaiman, 2019) Oleh karena itu terdapat beberapa keuntungan Inside pass diantaraanya yaitu
1) Mencetak angka dari jarak yang lebih dekat dengan ring, 2) Bisa dilakukan oleh semua posisi pemain, 3) Banyak gerakan yang bisa dilakukan sesuai dengan situasi dan kondisi dilapangan.

\section{METODE}

Metode dalam penelitian ini termasuk dalam metode deskriptif dengan teknik pengambilan data observasi atau survei. Teknik dari penelitian ini yaitu Analisis dokumenter berupa video pertandingan. Metode Analisis tersebut dilakukan untuk melihat keberhasilan dan kegagalan Inside Pass. Caranya dengan menghitung keberhasilan dan kegagalan Inside Pass dalam bentuk persentase pada setiap pertandingan tim Bola Basket Putri Universitas Negeri Jakarta. Sampel adalah bagian dari populasi. Sampel yang di gunakan yaitu total sampling yang digunakan seluruh pemain putri Universitas Negeri Jakarta yang bertanding pada liga Mahasiswa Basketball Nationals yang berjumlah 12 orang.

Kriteria Intrumen Inside Pass :

- Inside pass dikatan berhasil karena Passing dilakukan kedalam circle area dan pemain mampu menangkap dan mengontol bola tersebut, passing di sesuaikan dengan movement rekan satu tim dan timing yang pas agar pergerakan dan pasing bisa sesuai.

- Berhasil karena mampu mendapatkan peluang untuk finising seberti shooting,lay up dan under basket atau gerakan gerakan lain yang mampu menghasilkan peluang untuk mencetak point.

- Gagal karena tidak sesuai dengan taget,target tersebut yaitu pemain kehilangan passing karena bola di intercept atau di steal oleh lawan.

- Gagal karena kehilangan kesempatan untuk melakukan finishing disini pemain sudah mendapatkan bola di circle area namun karena defense yang terlalu ketat dan hal lainnya pemaiin tidak mengarahkan bola ke ring namun bola dipassing keluar circle. 


\section{HASIL DAN PEMBAHASAN}

Tabel 1. Tingkat keberhasilan dan kegagalan keseluruhan inside pass Tim basket Putri Universitas Negeri Jakarta

\begin{tabular}{ccc}
\hline \multirow{2}{*}{ UNJ VS } & \multicolumn{2}{c}{ INSIDE PASS } \\
\cline { 2 - 3 } & B & G \\
\hline UNAIR & 53 & 24 \\
UEU & 63 & 21 \\
\hline UNIKA & 53 & 30 \\
\hline$\sum$ & 169 & 75 \\
\hline
\end{tabular}

Tabel 2. Tingkat keberhasilan dan kegagalan Inside Pass pada Tim basket Putri Universitas Negeri Jakarta

\begin{tabular}{|c|c|c|c|c|}
\hline \multicolumn{5}{|c|}{ Inside Pass } \\
\hline $\begin{array}{c}\mathbf{U N} \\
\mathbf{J}\end{array}$ & & rhasil & & Gagal \\
\hline VS & $\begin{array}{l}\text { On } \\
\text { Tar } \\
\text { get }\end{array}$ & $\begin{array}{c}\text { Peluang } \\
\text { Finishi } \\
n g\end{array}$ & $\begin{array}{c}\text { Off } \\
\text { Targ } \\
\text { et }\end{array}$ & $\begin{array}{l}\text { Tidak ada } \\
\text { Peluang } \\
\text { Finishing }\end{array}$ \\
\hline $\begin{array}{l}\mathrm{UN} \\
\mathrm{AI} \\
\mathrm{R}\end{array}$ & 30 & 23 & 12 & 12 \\
\hline $\begin{array}{c}\text { UE } \\
\text { U }\end{array}$ & 38 & 25 & 4 & 17 \\
\hline $\begin{array}{l}\text { UN } \\
\text { IK } \\
\text { A }\end{array}$ & 30 & 23 & 12 & 18 \\
\hline$\sum$ & 98 & 71 & 28 & 47 \\
\hline
\end{tabular}

Keterangan :

- Berhasil karena Passing On Target

- Berhasil karena adanya peluang Finishing

- Gagal karena Passing Tidak sesuai target

- Gagal karena tidak ada peluang Finishing

\section{PEMBAHASAN}

Inside Pass adalah Passing yang diarahkan ke daerah pertahanan lawan dengan tujuan untuk mencetak point. Untuk melakukan inside Pass ini harus memperhatikan tiga hal penting yaitu 1) Movement 2) Timing 3) Catching . Dari ketiga hal tersebut dapat dijelaskan yaitu yang pertama mengenai Movement atau pergerakan, hal itu pergerakan dapat di bagi menjadi dua yaitu pergerakan lawan dan juga pergerakan rekan satu tim, artinya pemain harus paham dalam hal keduanya agar pemilihan bentuk passing yang dilakukan akan sesuai dengan kedua hal itu. Pemilihan passing yang sesuai maksudnya adalah dilihat berdasarkan situasi dan kondisi dilapangan apakah defender tinggi atau Pemain dijaga ketat dan lain sebagainya. Kemudian yang kedua mengenai timing saat pemain sudah dalam posisi siap melakukan passing pergerakan rekan satu tim pun harus sesuai agar pergerakan passing dapat berjalan bersamaan dengan pemain yang bergerak untuk meminta bola. Yang ketiga yaitu Catching hal ini sangat penting karena pemain harus mampu menagkap bola dan mempertahankan bola tersebut karena passing and catching adalah kedua teknik dasar yang harus dipenuhi oleh seorang pemain basket.

Dilihat dari hasil inside pass yang telah dilakukan secara keseluruhan total dari 244 kali inside pass, keberhasilan 169 atau 69\% dan kegagalan 75 kali atau 31\%. Masingmasing inside pass yang dilakukan di setiap pertandingan cukup banyak keberhasilannya seperti pertandingan UNJ melawan UNAIR jumlah inside pass yang dilakukan total 77 kali dari jumlah tersebut 53 kali berhasil atau $68,83 \%$ dan kegagalan 24 atau $31,16 \%$. Pertandingan ke dua yaitu UNJ vs UEU total inside pass yang dilakukan berjumlah 84 kali dari data tersebut yang berhasil berjumlah 63 kali atau $75 \%$ dan kegagalan 21 kali atau $25 \%$. Dan yang terakhir pertandingan melawan UNIKA jumlah inside pass yang dilakukan 83 kali dari data tersebut keberhasilan berjumlah 53 atau $63,85 \%$ dan mengalami kegagalan 30 kali atau 26,14\%. Jumalah Inside pass yang dilakukan tidak jauh berbeda di setiap pertandingannya, namun perbedaan cukup jauh dari dua game UEU dan UNIKA saat melawan UNAIR inside pass cenderung lebih sedikit namun secara keberhasilan memiliki data yang sama.

Berdasarkan analisis yang dilakukan selama pertandingan yang dijalani oleh tim basket puteri UNJ pada liga Mahasiswa 
Basketball Nationals 2019 dari segi teknik sudah bagus yaitu pemain mampu melakukan inside pass kedaerah circle lawan, dan tidak jarang dapat menghasilkan peluang finishing. Namun kegagalan Inside Pass yang dilakukan lebih sering dikarenakan pemain tidak mampu melakukan passing ke dalam karena pemilihan teknik passing yang salah, seperti saat pertandingan melawan UNAIR, lawan melakukan defense man to man yan cukup ketat namun pemain UNJ banyak melakukan chest pass tentu saja akan sulit dan terjadinya kesalahan sehingga lawan dapat melakukan serangan balik.

Selain itu dari teknik strategi UNJ lebih sering menggunakan Inside pass hanya sebagai umpan untuk menarik lawan bergerak kearah dalam memenuhi area pertahanan, namun saat bola sudah di dalam pemain tidak dalam posisi yang siap dan akhirnya pemain bingung dan terjadi kebuntuan, Padahal berdasarkan statistik empat Big Man pemain UNJ rata- rata menghasilkan 6 point per game. Tentunya dengan hal tersebut inside pass ini dapat dimanfaatkan oleh tim UNJ.

Penggunaan inside pass ternyata sesuai dengan yang telah dijelaskan sebelumnya, bahwa kekuatan menggunakan inside pass dapat merusak pertahanan dari luar dan dalam, Inside pass cukup menghasilkan banyak point terutama tim UNJ memiliki Big Man yang dominan dalam mencetak angka. Seperti saat melawan UNAIR pemain Big man dominan mencetak angka,seperti tercatat di statistik pemain big man total mencetak 21 point.

Ancaman menggunakan Inside pass yaitu karena lawan sudah mengetahui target point berada pada big man melalui inside pass justru hal ini akan menjadi bumerang karena lawan akan dengan mudah membaca permainan.

Berdasarkan hasil deskripsi data keberhasilan inside pass melawan UEU lebih banyak yaitu 63 kali, hal ini dikarenakan inside pass dijadikan sebagai umpan untuk menarik pertahanan lawan sehingga beberapa kali mendapatkan finishing three point. Selain itu pemain cukup banyak melakukan pergerakan di circle area sehingga banyak mendapatkan inside pass.

Keberhasilan inside pass saat melawan UNAIR dan UNIKA masing- masing berhasil melakukann inside pass sebanyak 53 kali. Saat pertandingan melawan UNAIR pemain banyak melakukan pergerakan di daerah circle are seperti $v$ cut, peak and roll, post move terutama untuk big man yang cukup mendominasi saat pertandingan.

Kemudian saat melawan UNIKA Inside pass sangat berguna untuk menarik pertahanan lawan sehingga banyak pemain UNIKA yang terpancing untuk melakukan foul, dan hal ini dapat dimanfaatkan oleh tim UNJ, tercatat di statik point dari 12 kali tembakan bebas 9 berhasil dan 3 gagal.

Untuk kegagalan Inside pass disetiap pertandingan hampir sama yaitu banyak dilakukan karena tidak sesuai target yaitu terkena intercept, kehilangan bola ataupun kehilangan kesempatan untuk melakukan finishing.

Berdasarkan data yang didapatkan keberhasilan Inside Pass yang dilakukan UNJ secara keseluruhan mencapai 69,26\% dan kegagalan mencapai 30,73\% hal ini menyatakan bahwa keberhasilan lebih besar dibandingkan dengan kegagalan. Jika Inside Pass ini dapat dimaksimalkan bahkan akan menguntungkan untuk tim tersebut.

Berdasarkan hasil pertandingan yang telah dilakukan UNJ vs UNAIR terjadi 77 kesempatan melakukan inside pass 53 berhasil dan 24 gagal berdasarkan hasil tersebut maka keberhasilan sebesar $68,83 \%$ dan mengalami kegagalan sebesar 31,16\%. Dari jumlah keberhasilan Inside pass sebanyak 53 kali cukup mengahsilkan banyak point, hal ini dipengaruhi oleh pemain yang cukup sering melakukan gerakan-gerakan meminta bola di daerah circle seperti post up, peak and roll, cutting dan gerakan lain sehingga bola dapat dialirkan circle area. Inside pass ini juga selain berguna untuk mencetak point di circle area, inside pass membantu untuk menarik pertahan lawan sehingga daerah luar circle menjadi longgar dalam penjagaan, menurut (Courel-Ibáñez et al., 2018) saat bola sudah di dalam circle area, semua pemain akan membantu untuk 
melakukan pertahanan, atau melakukan weak side, sehingga terjadi kekosongan penjagaan di bagian luar, harusnya hal ini dapat dimaksimalkan sebagai usaha pemain UNJ untuk mencetak angka, namun berdasarkan staistik yang ada dari 14 kali percobaan hanya 2 yang menghasilkan point. Selain itu tidak semua pemain mimiliki passing yang baik sehingga tak jarang passing yang dilakukan justru tidak sesuai sasaran sehingga passing itu bisa di manfaatkan oleh lawan untuk melakukan fast break atau searangan balik.

Kemudian pertandingan kedua yang dijalani UNJ yaitu melawan UEU Inside pass yang dilakukan yaitu sebanyak 84 kali, inside Pass yang berhasil yaitu 63 dan 21 kali gagal atau keberhasilan $75 \%$ dan kegagalan mencapai $25 \%$, di pertandingan kedua ini inside pass yang dilakukan cukup banyak karena lawan tidak memiliki Big man yang dominan sehingga pemain Big man UNJ dapat melakuakan pergerakan di dalam circle area, seperti diketahui pada Liga mahasiswa ini inside pass lebih dominan didaptkan oleh pemain big man, namun meskipun dominan dalam mendapakan point dari dalam, UEU dapat melakukan serangan balik dan membalas UNJ dengan tembakan tiga angka yang berkali-kali sehingga cukup membuat UNJ kesulitan untuk mengejar ketertinggalan, dan seperti diketahui dari statistik pertandingan dari 8 kali temabakan tiga angka yang dilakukan pemain UNJ hanya tiga yang berhasil, dan hal ini yang membuat tim UNJ mengalami kekalahan, kuat secara penyerangan di dalam namun leman penyerangan dari luar.

Pertandingan ketiga UNJ melawan UNIKA inside pass yang dilakukan UNJ yaitu berjumalah 83 kali, yang berhasil sebanyak 53 dan gagal sebanyak 30 kali. Persentase $63.85 \%$ dan mengalami kegagalan sebesar $36.14 \%$. Inside Pass yang dilakukan dapat menghasilkan point yang seimbang antara small man dan bing man, hal ini berjalan dengan baik karena pemain big man pun berusaha melakukan pergerakan di circle are seperti cutting dan peak and roll sehingga mereka memiliki kesempatan untuk lay up atau menembak di dalam circle area, diantara tiga pertandingan jumlah tidak adanya peluang finishing di pertandingan melawan UNIKA ini menjadi yang terbanyak yaitu 18 kali, yang harusnya inside pass ini dapat dimanfaatkan untuk mendapatkan peluang finishing tapi pemain tidak dapat melakukan hal tersebut. Dari beberapa penjelasan tersebut maka peneliti membuat kesimpulan menggunakan analis SWOT sebagai berikut:

- Kekuatan Tim UNJ

Inside Pass yang dilakukan dapat menghasilkan point.

Inside pass yang dilakukan banyak di peroleh ole Big man dan menghasilkan point.

- Kelemahan Tim UNJ

Tidak semua Pemain memiliki inside pass yang baik. hal ini dapat mengakibatkan trun over yang menghasilkan keuntungan untuk lawan.

- Peluang Tim UNJ

Inside pass dapat dijadikan system penyerangan untuk merusak pertahanan dari luar dan dalam, hal ini dapat digunakan dan disesuaikan dengan komposisi Pemain ynag dimiliki

- Ancaman Tim UNJ

Salah satu penyebab kegagalan Inside pass yaitu lawan sudah mengetahui sehingga tidak selalu berhasil, namun hal ini dapat dikombinasikan dengan berbagai gerakan sehingga inside pass ini dapat dengan mudah dilakukan.

\section{KESIMPULAN}

Berdasarkan analisis Peneliti Inside Pass yang dilakukan oleh Universitas Negeri Jakarta sudah baik bagaimana Inside Pass Ini tujuannya mengarahakan bola ke area circle lawan dan berusaha mencetak point dari jarak yang lebih dekat dengan ring tingkat keberhasilan mencapai $69 \%$ dan kegagalan $31 \%$ dan berdasarkan data yang diperoleh peluang untuk finishing rata-rata mecapai 71 kali atau $42 \%$. Persentase ini cukup besar dan bisa dijadikan salah satu strategi oleh UNJ dalam membuat system penyerangan yang mengutamakan Inside Pass. 
SARAN

Berdasarkan hasil kesimpulan penelitian maka dapat diajukan saran sebagai berikut:

1. Pengulangan latihan Inside pass dilakukan secara berulang-ulang agar pemain dapat eradaptasi dengan pergerakan,timing serta catching bola yang baik.

2. Latihan Finishing di circle area lebih diperbanyak karena tingkat untuk mendapatkan peluang finishingnya mencapai $42 \%$.

3. adanya komunikasi dan kerjasama tim yang baik untuk dapat melakukan Inside Pass yang baik

4. Pemain harus bisa memecahkan masalah di dalam suatu pertandingan,jika pattern yang digunakan di tidak berjalan baik maka pemain harus mampu improve berdasarkan situasi dan kondisi yang ada.

5. Perbaiki setiap kesalahan di pertandingan dilatihan selanjutnya agar tim dapat terus berkembang dan siap menghadapati tim-tim lain yang lebih kuat.

\section{DAFTAR PUSTAKA}

Ambarukmini. et al. (2007). Pelatihan fisik level 1.

Iman sulaiman. (2019).. Bahan Pelatihan Tingkat Dasar. https://doi.org/10.1055/s-20081040325

KBBI. (2019), analisis. KBBI. (2019) Pengertian Analisis, https://kbbi.web.id/analisis

Lembaga Administrasi Negara. (2008). Teknik-teknik Analisis Manajemen (Issue 62 21).

.(Muhajir dan Much, 2007)

Purangga (2016) G.P Purangga (2016) Analisis SWOT, http://repo.iaintulungagung.ac.id/3657/3/BAB II revisi.pdf

Rose, L. (2013). Winning basketball fundamentals.

http://www.worldcat.org/title/winning -basketball-

fundamentals/oclc/783142365\&refere $\mathrm{r}=$ brief_results

Sugiyono, P. D. (2012). Metode Penelitian(Mixed Method).pdf (M. . Sutopo (Ed.)).

Vermeil, A. (1988). Program design:

Training components for basketball. National Strength and Conditioning Association Journal, 10(6), 64-66. https://doi.org/10.1519/07440049(1988)010<0064:TCFB >2.3.CO; 2

Wissel, H. (2012). Steps to Success 3rd ed. In Modern Steel Construction (3rd ed., Vol. 43, Issue 2). 